\title{
The Abrasion-Meter
}

\section{A Device for Determining the Cutting Efficiency of Abrasive Wheels \\ By Raymond Francis Yates}

IT is difficult to overestimate the importance of the modern abrasive wheel in the industry of today. Electrothermic abrasives with their unprecedented hardness, extreme sharpness and fast cutting power have made the grinding wheel an absolutely indispensable article in the industrial world.

Since the advent of the modern abrasive wheel an its important relationship to industry, the value of a machine that could be used in determining the true cutting efficiency of wheels has been recognized. Such a machine would enable manufacturers to conduct tests which would give them valuable data in regard to the nature of the grinding various substances. Such a mac benefit to the mechanical world at large, owing to the fact that it would equip manufacturers with a device which would give reliable results to guide them in pur- used for various purposes. Silicate wheels are bonded by silicate of soda which has a viscid, tacky nature and which, when dehydrated, forms a solld mass. The abrasive particles are mixed with the silicate of soda and after being shaped are placed in a baking oven where dehydration takes place. Other bonds are used such as shellac and rubber but their use in the indus trial field is limited to very special processes and for this reason they will not be considered.

The bond of an abrasive wheel is an extremely important consideration and its nature either contributes or detracts from the efficiency of the whel. If the or bond is too hard for the work that the whe is doing setting rapidly enough and they therefore remain in place until they become very dull. On the other hand, if the bond is too soft the particles lose their connection acts as the fulcrum of a lever whose opposite end rests upon the abrasive wheel under test, is mounted at one end of the base. Fixed to the free end of the lever is a small copper block through which a $1 / 8$-inch hole is drilled. At the side of this hole another hole is drilled so that it will break into the first hole. The second hole is drilled with a No. 14 drill and the drill is withdrawn just before it breaks through at the bottom. At right angles to the first hole another but longitudinal hole is drilled with a No. 28 drill. This is tapped out with an 8-32 tap to accommodate a set screw which holds the small cylindrical test piece (1/ in, diam $\times 1$ in long) in place. The large hole is uset ac $x$ in lame in place The large hale is used to so that any rise in temperature of the test piece will be conducted to the bulb of the thermometer and indicated in degrees on the scale. To make the thermal connec-
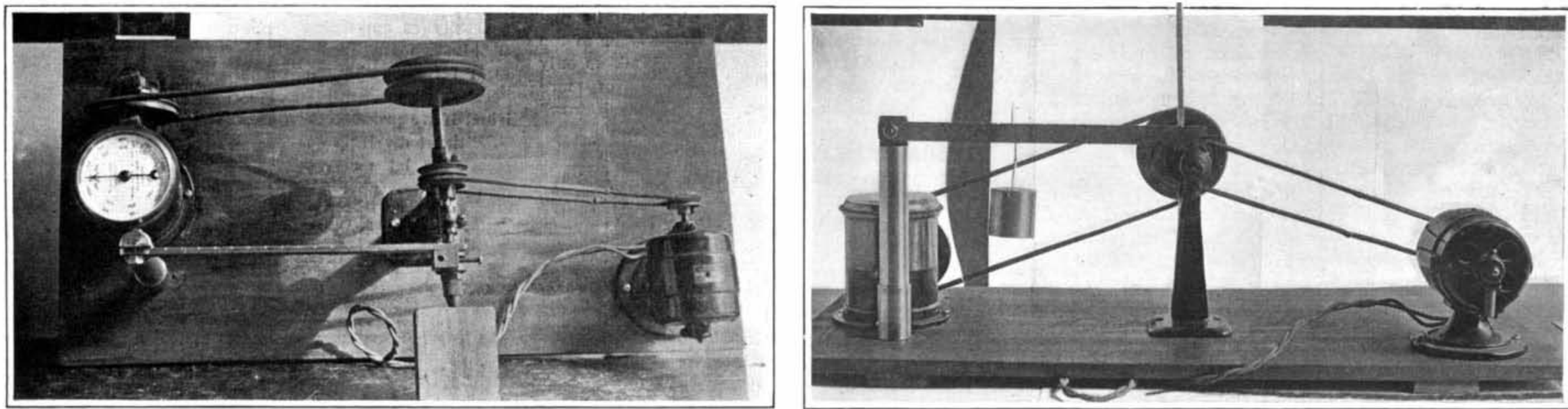

Vertical and side views of the Yates Abrasion-Meter

chasing those wheels best adapted for specific purposes.

The author recently devised and constructed an abrasive testing machine in the laboratories of the Amercan Society of Experimental Engineers and by the us of this machine some very interesting data was obtained with grinding wheels of various grits, grades and bonds. It was not only possible to plot interesting curves with the device, but a reliable formula was devised by means of which the abrasive efficiency of varlous wheels may be stated in actual figures. If various wheels may be stated workman is able to grind a greater number of brass castings on a certain wheel in one day than on another wheel of a different grade, the manufacturer, of course, decides in favor of the wheel which produces the most work. This is a practical test and we must grant that the manufacturer is right in choosing the wheel which performs the most work, but, on the other hand, it must be admitted that this is by no means a scientific test that will give absolutely reliable results. The value of a machine which would give results in The value of a machine which
actual figures can be appreciated.

Before describing the machine originated and constructed by the writer, a few words will be said regarling the general nature of abrasive wheels and their manufacture.

Wheels are manufactured with various grits, grades and bonds. The "grit" of a wheel is the size of the abrasive particles which go to make it up. If a wheel is 80 grit, 80 signifies that the abrasive particles which make up the wheel are just able to pass through a screen having 80 meshes to the square inch. A wheel in 20 grit for instance, would be a very coarse wheel and a wheel of 200 grit would be very fine.

By "grade" is meant the temper or degree of hardness of the abrasive used. The electrothermic processes for the production of modern abrasive substances such as Alundum, Carborundum, Aloxite and Crystallon are under such perfect control that grades of varying are unders hardness can be produced. The grades are indicated by letters and each manufacturer of abrasive wheels has a certain number of letters which cover his
grades running from extremely hard to soft.

grades running from extremely hard to soft.
The "bond" of a wheel is the substance that binds the abrasive particles into a solid mass. Various bonding substances are used. Certain fusible vitrifying clays are used. These clays are mixed with abrasive particles, pressed into shape under hydraulic pressure and placed in a vitrifying kiln where fusion of the clays takes place, resulting in a hard matrix which holds the abrasive particles in place. Vitrified wheels are widely with the wheel and fall off before their sharpness has disappeared. In the first case, great friction will be developed and the cutting efficiency of the wheel will be considerably reduced. In the second case, the whee will cut freely and easily but will wear away very rapidly.

The machine constructed by the author for the determination of abrasive efficiency is shown in the photographs. By the use of this machine, all the figures necessary to calculate the abrasive efficiency are made available. The machine is very simple, and although it was not in accordance with the author's idea of a perfect device, it at least served the purpose of proving that it would be a useful article and that it could be relied upon for results.

A small grinding head is used to mount the whee upon and this is driven by a small power motor. A rheostat is used in connection with this machine for obtaining various speeds. Belted to the grinding head, with a ratio of $1: 1$ is a tachometer. A standard which

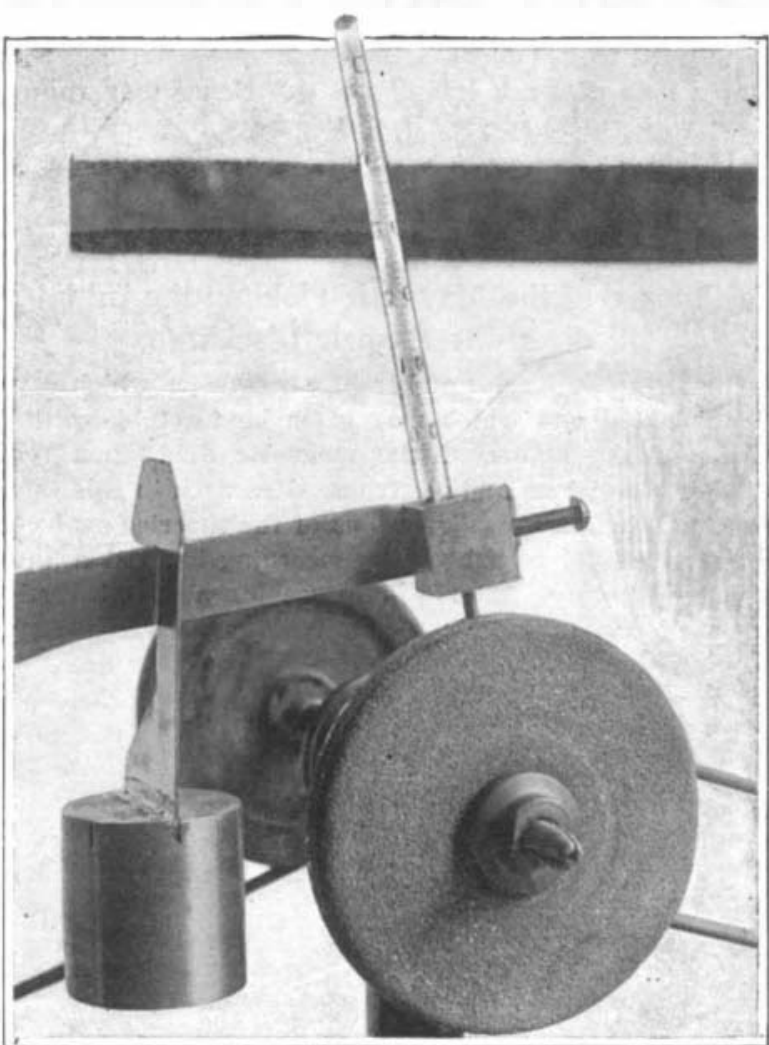

Detail of the Yates Abrasion-Meter tion between the thermometer and the test piece more perfect mercury is poured into the hole before the thermometer is put in place. $A$ one-pound weight is suspended from the lever by a hook which seats in notches filed at every $1 / 2$ inch along the top of the lever so that the weight can be adjusted and therefore the pressure upon the wheel can be regulated. The close-up photograph will reveal the detalls of the device.

The following factors can be determined by the use of the machine described:

(1) Temperature in degrees Centigrade

(2) Amount of metal removed from the test piece

(3) Surface velocity of the wheel in feet.

(4) Pressure or load on the wheel in pounds.

(5) Time in minutes.

The following formula is used in determining the efficiency of the wheel:

Where:

$$
\text { Efficiency }=1 \div t v p \quad T \text {, }
$$

$$
\begin{aligned}
& t=\text { temperature } \\
& l=\text { metal removed, } \\
& v=\text { surface velocity, } \\
& p=\text { pressure or load, } \\
& T=\text { time }
\end{aligned}
$$

Some curves were plotted by the use of this machine which showed the relation between temperature and time with steel stock at given pressures and speeds with different grades of wheels. An interesting curve in this respect was plotted for conditions when the speed was 600 R.P.M., which gives a surface velocity of $4471 \mathrm{ft}$. per minute, The wheel used was Carborun. dum 3 in in diameter and 80 grit, and the load was 3.5 pounds. The rise in temperature was fairly rapid until 31 degrees $C$. was approached. At this point the curve rounded out.

A somewhat interesting result shown in Fig. 1 was obtained with the same wheel by increasing the speed of the motor to 1,000 R.P.M. and reducing the load to $1.5 \mathrm{lbs}$. The time element was also extended to 3 minutes. The temperature mounted rapidly until it reached 34 degrees $C$. At this point, the curve flattened out. Although the temperature mounted more quickly in this test than it did in the previous one, over four times as much metal was removed from the test piece.

It is well to mention at this point that the temperature is a factor that is generally controlled by friction. If the abrasive particles of the wheel do not break away from their setting after losing their sharpness the wheel rubs the surfaces of the metal without cut- 
ting and this produces friction. Friction is always attended by a rise in tem perature. In the average case, the temperature for a given time can be taken as some indication of the cutting efficiency of an abrasive wheel. The curve in Fig. 2 is an interesting one and it shows how excessive speed of a wheel will reduce its cutting power. The wheel used was a Carborundum, grade $J$, grit 00 and had Carborundum, grade $J$, grit 60 and had a dlameter of 3 inches. The test was started at 100 R.P.M. and the speed gradually increased to 1,700 . Up to 1,300
R.P.M. the rise in temperature was gradR.P.M. the rise in temperature was gradual but at this point it mounted suddenly to $38 \mathrm{deg}$. The test showed that the most

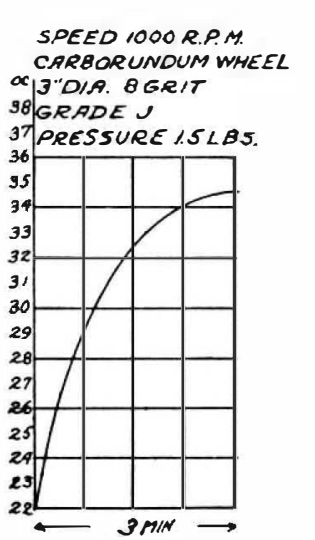

Fig. 1

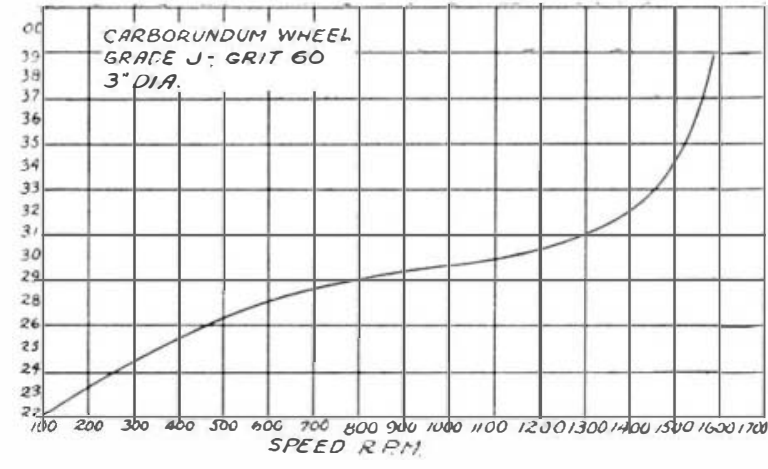

Fig. 2 used with this particular stock was in the neighbor- forth in this treatment as a guide. The author behood of 1,300 R.P.M.

Fig. 3 shows the results obtained with an Aloxite wheel of 180 grit. The pressure was 1.5 pounds and the speed 600 R.P.M. In this test the temperature mounted somewhat abruptly to $440 \mathrm{deg}$. in 3 minutes. The result of this test proved beyond question that this wheel hatl a particularly low cutting efficiency whe used in connection with stock of the nature of that

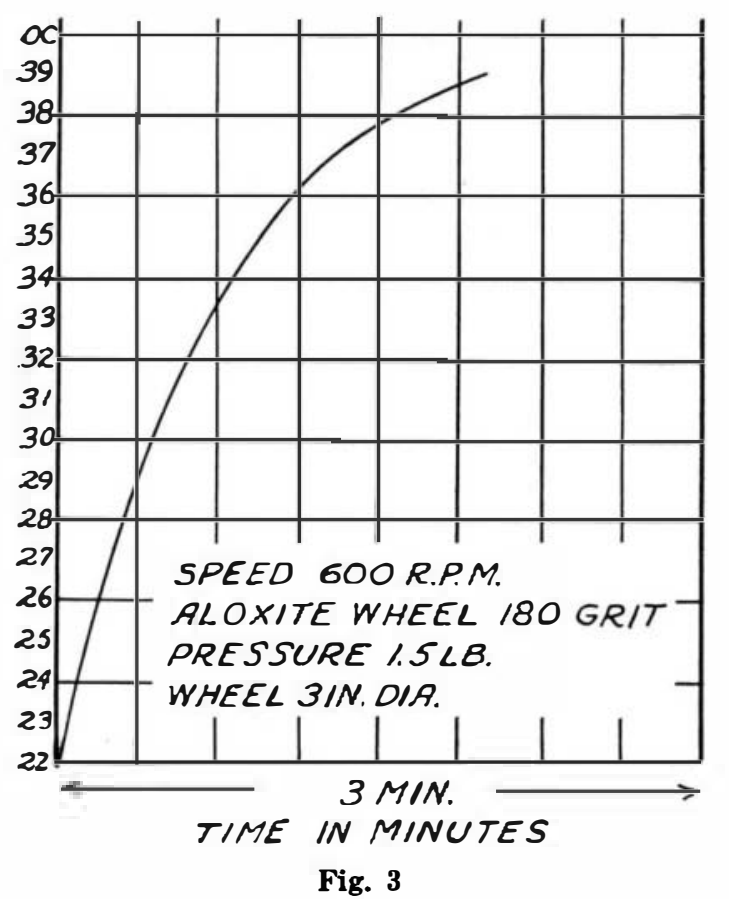

which constituted the test piece. The low efficienc was probably caused by the fine grit of the abrasive wheel which was used.

An interesting test was made with a 3-inch Carborundum wheel 80 grit, grade J. The result of thi test is shown in Fig. 4, and it will be noticed that the speed was 600 R.P.M. and the pressure $1.5 \mathrm{lbs}$. The test piece was steel stock and the temperature took very normal rise to $35 \mathrm{deg}$. in 3 minutes. Other inter-

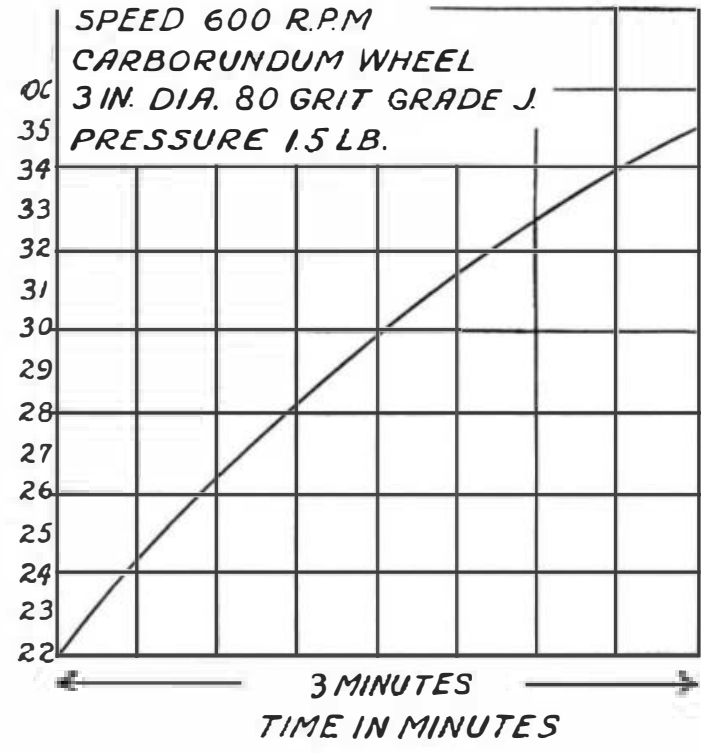

Fig. 4 esting charts could be plotted which would show the relationship between temperature and pressure as well as speed and temperature at constant pressures; also as speed and temperature at constant pressures; also and the temperature.

The few tests conducted by the author were by no means exhaustive and it is hoped that those who are interested in the subject will carry the work of perfection and investigation further, using the data set forth in this treatment as a guide. The author be lieves in the proming an a device into a reliable testing machine to determine the
abrasve efficiency of wheels when used to grind various substances.

\section{Measurement of Heat Losses Through Insulating Materials}

ThE author-points out that progress in the preparation of non-conducting materials depends upon the existence of reliable data, and indicates the best methods of obtaining same.

Rough comparisons are misleading because they do not distinguish between losses due to conductivity, convection, and radiation. The latter should not be neglected. Tests carried out on asbestos insulation in technical institutions have been examined and found of little practical value as they only refer to comparative conductivity of different materials.

Tests with continuous heat currents have been carried out according to the methods proposed by Nusselt, Gröber, Poensgen and van Rinsum. They all employ heat produced and measured electrically for determining the quantities of heat passing through test-pieces which are classified according to shape, such as hollow spheres, hollow cylinders, etc., and plates.

Nusselt uses hollow test-pieces with internal electric heating coils. The heat-loss-coefficients for various temperatures can thus be determined from one experiment He has worked out the analogy between the lines of the heat current and the lines of force for the electric current, and made the method applicable to all hollow vessels. The measurements range from $59^{\circ} \mathrm{F}$. to $1,040^{\circ}$ F. Gröber has extended the measurements for refrigerating practise to $-288^{\circ} \mathrm{F}$, and van Rinsum has tested

The heat-loss-coefficients for the whole series from $288^{\circ} \mathrm{F}$. to $1,832^{\circ} \mathrm{F}$. showed an increase proportionate to the temperature. The experiments with high temperatures made by van Rinsum are the most reliable, but they apply to specially made segments only.

The conductivity of hollow cylinders for protecting steam pipes was determined. Test cylinders were made of such a length that the axial losses were comparafor the heat-loss-coefficients in which this source of inaccuracy is allowed for.

Gröber tested two similar plates with an electric edges of the plates are prevented by means of Poensgen's electrically heated protecting rings, but the losses in testing good non-conductors due to the width of the testing good non-conductors due to the width of the
slit used by Poensgen is considerable, and a narrower slit used by Poensgen is
slit should be substituted.

Tests were carried out in the Government Testing Station at Charlottenburg according to Gröber's method, but protecting rings were not used, and the heat losses were allowed for in a formula which is identical with van Rinsum's for hollow cylinders.

The author shows how the two-plate and the hollow cylinder methods can be made applicable to very high temperatures as required for experiments with firebricks instead of calorimeters formerly used. Goerens has improved the experiment by introducing electric heaters, thermo-piles built into the material, and a protecting ring whereby the flow of heat is directed to the test-plate,-Zeitschrift des Vereines Deutscher Ingenieure.

\section{Celebes Ore Deposits}

A chrarical analysis shows that the Celebes ironores are equal in value to those of New Caledonia and the Philippines, and superior to those of Cuba. It is estimated that at least 1 milliard tons of ore are contained in the island. Experts consider that the elecmanufacture of the Celebes ores, and about 300,000 h.p. from the water-power of the Matili River is a vailfirebricks up to $1,832^{\circ} \mathrm{F}$. tively small. He was the first to develop a formula heater inserted between them. Heat losses at the tro-metallurgic process is the most suitable for the able for generating the necessary current. It would be possible to produce $500,000 \mathrm{t}$. of pig-iron or of steel annually from about 1 mill. $t$. of ore, but it would be necessary to convey $170,000 \mathrm{t}$. of coal up to the works. It will probably be found expedient to construct a cable railway for this purpose, and the cost of the steel works, railway, harbor works, and power-station is estimated at Fl125 mill. Dr. Heber conclules his article by an. Dr. Heler conclyes his article by a detailed account of the nickel ore deposits in the island. Between 1825 and 1915 the amount of nickel used in industries increased from 2,500 to 175,000 tons.Wirtschaftsdienst.

A New Dew-Gage (Drosometer)*

Professor Eredia of the Central Meteorological Bureau at Rome has devised a new drosometer which he describes in L'Agricoltura Coloniale.

The device consists essentially of a hemispherical Dewar cup having its double walls silvered, and with an interior area of $100 \mathrm{sq} . \mathrm{cm}$. ( $C$ in Fig. 1). The deposit of dew is measured in this cup. To prevent evaporation or an unforeseen rain from invalidating the results, in case measurement cannot be made at once, the cup is fixed in a wooden box in such a manner that the rim of the cup is flush with the box cover which has cut in it a circular opening precisely equal to the area of the circular aperture of the cup, and which may be closed automatically.

The closing device, which, by the way is applicable to many other instruments, consists of a clock-movement $H$, placed within the box, and may be a simple alarm clock whose gong and hammer have been removed and replaced by a rod, $t$, fixed to the spring of the alarm. This rod is hinged at its upper end, to a lever whose fixed end is at $l$, and whose free end carries a pin, $b$, which acts as a stop to the movable circular cover. This cover is attached to a spring, $r$, which tends to turn it about the pivot $p$ as soon as the stop no longer opposes its resistance.

The clock-work is wound up, the alarm release is set to go off precisely at sunrise; the movable lid is opened and remains "set" with its spring tense, against the stop. Thus prepared the apparatus is placed on

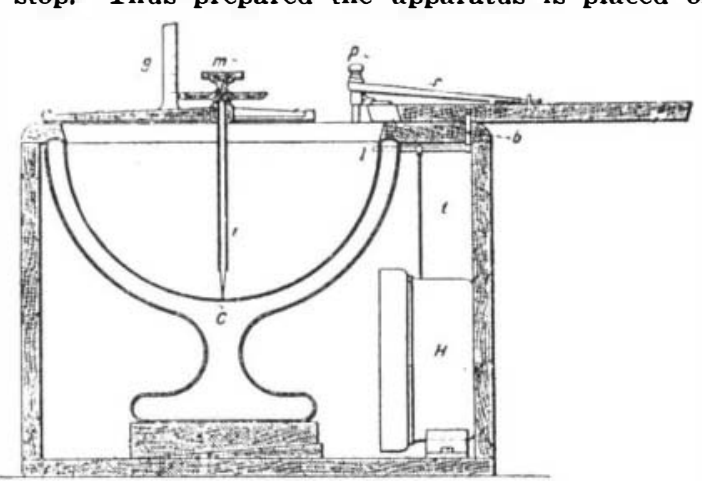

Eredia's Drosometer or Dew Measurer

the ground at the point where measurements are to be made. The cup remains exposed throughout the night, if the meteorological conditions are favorable dew is formed in the cup, and at dawn the lid hermetically closes the cup preventing all evaporation.

In order to measure the amount of water condensed one may not pour it out into a graduated measure as this would cause a loss of liquid; to weigh it would consume some little time. Prof. Eredia employs an iron tripod whose extremities are fitted with points that fit on three metallic disks countersunk in the fixed box cover. The center of the tripod, which coincides with the axis of the cup, consists of a screw in which fits a micrometer screw having a milled head, $m$, and terminating in a sharp point at its lower end. To the milled head is attached a divided circle whose edge is against a vertical scale rod, $g$, divided into millimeters. The zero on the scale, $g$, corresponds to the condition when the point of the screw is in contact with the bottom of the cup. This kind of spherometer permits one to read to the 50th and even to the 100th of a millimeter.

To make a reading the screw is turned until its lower point just touches the surface of the water in the bottom of the cup, a position which is easily determined since the point is reflected in the water. When the point and its image are exactly in contact one notes the height of the water on the graduated scale, $g$ and on the divided circle. Thus one determines the height, $h$, of a spherical segment of calculable volume. A table prepared in advance eliminates the repetition of this calculation.

-Translated for The Scientific AMERican Supplament from La Nature (Paris). 